\title{
PENGEMBANGAN JARINGAN KOMPUTER NIRKABEL (WiFi) MENGGUNAKAN MIKROTIK ROUTER (STUDI KASUS PADA SMA PGRI AIKMEL)
}

\author{
Lalu Delsi Samsumar' ${ }^{1}$, Sofian Hadi $^{2}$ \\ ${ }^{1)}$ Dosen STMIK Mataram, ${ }^{2)}$ Mahasiswa PS Teknik Komputer STMIK Mataram \\ Sekolah Tinggi Manajemen Informatika Komputer (STMIK) Mataram \\ Jln. Pelor Mas III Kampus STMIK ASM Mataram \\ lalu.ellsyam@gmail.com
}

\begin{abstract}
Information technology has penetrated into various fields including educational institutions, then the need for information is currently increasing. Currently everyone needs information in a fast, short and accurate time, therefore it takes media and tools that can support the work with various applications, media, and easy ways to access the information, one of them is internet connection with hotspot service or wireless-based computer network (WiFi). SMA PGRI Aikmel is one of the private schools that have many enthusiasts because it has adequate facilities in conducting teaching and learning process. Along with the increase of public trust to this educational institution, hence required a wireless based computer network to support performance at academic part and to improve teaching and learning activity. By leveraging rapid technological advancements to enable equipment using cable technology to be replaced with wireless technology such as radio frequency media. This research is a qualitative research. Data were collected by observation, interview, documentation, and literature study. With the Network Development Live Cycle (NDLC) method, this study examines the development of wireless networks using Mikrotik devices and cisco packet tracer applications as simulation media from the development of network schemes.
\end{abstract}

Keywords : Wireless network, Wifi, Mikrotik

\section{Pendahuluan}

Seiring dengan berkembangnya teknologi informasi saat ini yang sudah merambah ke berbagai bidang termasuk di bidang pendidikan, maka kebutuhan akan informasi semakin meningkat. Saat ini setiap orang membutuhkan informasi dalam waktu yang cepat, singkat dan akurat oleh karena itu dibutuhkan sarana yang dapat mendukung teknologi informasi tersebut, salah satunya adalah koneksi internet dengan layanan hostpot. Dengan Hostpot, akses internet dapat dinikmati selama berada di area hostpot tanpa harus menggunakan kabel Adanya layanan hostpot dilingkungan sekolah akan mempercepat akses informasi baik guru, siswa dan karyawan.

Saat ini SMA PGRI Aikmel sudah menggunakan koneksi internet dari ISP Telkom dengan kapasitas bandwitdh 10 Mbps dan digunakan oleh 2 laboratorium komputer yang masing-masing laboratorium memiliki 30 komputer. Dengan kapasitas ini seharusnya tidak terjadi masalah jika hanya untuk mengakses internet seperti mencari informasi dan chating. Namun muncul masalah koneksi lambat jika banyak klien menggunakan secara bersamaan. Selain itu, dalam jaringan ada situs-situs dengan konten yang tidak baik bagi perkembangan moral dan etika sehingga sangat dibutuhkan adanya sistem keamanan jaringan. Selain itu kurang lebih 20 pengguna jaringan wireless tidak menggunakan pengamanan atau user dan password serta belum adanya konfigurasi user dengan profile yang berbeda hal ini dapat menyebabkan koneksi internet tidak stabil. Guna mengatasi masalah ini dapat dilakukan pengembangan jaringan dengan mikrotik router OS yang berfungsi sebagai pengatur jalur lalu lintas data untuk mengatasi masalah performa jaringan. Mikrotik router OS merupakan sistem operasi Linux base yang diperuntukkan sebagai network router dan didesain untuk memberikan kemudahan bagi pengguna. Administrasinya dapat dilakukan melalui Windows Application dan instalasi dapat dilakukan pada komputer (PC). Dengan demikian tujuan dari penelitian ini akan mengembangkan jaringan wireless pada SMA PGRI Aikmel yang memanfaatkan perangkat mikrotik router dengan sistem operasi mikrotik router OS sehingga jaringan yang ada dapat digunakan dengan aman dan sesuai kebutuhan.

\section{KAJIAN LITERATUR}

\section{II.1 Teknologi Jaringan Komputer}

Jaringan Komputer adalah sebuah jaringan yang terdiri dari dua komputer yang saling terhubung dengan sebuah media sehingga komputer-komputer tersebut dapat saling berbagi resource dan saling berkomunikasi. Kenyataannya sebuah network biasanya terdiri dari banyak komputer (lebih dari dua). Jaringan komputer muncul dari adanya kebutuhan untuk berbagi data diantara para pengguna, dan memiliki kemampuan dalam memproduksi beberapa jenis informasi yang berupa data, spreadsheet atau grafik. Sedangkan konsep dari komputer-komputer yang saling berbagi resource dikenal dengan istilah networking. Komputer-komputer yang termasuk kedalam sebuah jaringan dapat saling berbagi resource berupa : Data, Pesan, Printer, mesin Fax, Modem dan perangkat-perangkat lain (Tanenbaum, 1997).

Tujuan penggunaan jaringan komputer adalah: a) untuk berbagi sumber daya, sepert berbagi printer, CPU, memori, hardisk, dan lain-lain, b) untuk komunikasi, seperti e-mail, instant messaging, chatting, dan lain-lain, c) untuk mengakses informasi, seperti web browsing, file 
server, dan lain-lain. Untuk mencapai tujuan yang sama maka setiap bagian dalam suatu jaringan akan meminta dan memberikan layanan. (Sofana, 2012)

\section{II.2 Klasifikasi Jaringan}

Jaringan diklasifikasikan berdasarkan jarak dan lokasi, yaitu Local Area Network (LAN), Metropolitan Area Network (MAN), Wide Area Network (WAN), Internet, dan jaringan tanpa kabel (Wireless).

Tabel 1 Klasifikasi jaringan berdasarkan jarak

\begin{tabular}{ccc}
\hline Jarak & Lokasi & Jenis Jaringan \\
\hline $10 \mathrm{~m}$ & Ruangan & LAN \\
$100 \mathrm{~m}$ & Gedung & LAN \\
$1 \mathrm{~km}$ & Kampus & LAN \\
$10 \mathrm{~km}$ & Kota & MAN \\
$100 \mathrm{~km}$ & Negara & WAN WAN \\
$1.000 \mathrm{~km}$ & Benua & INTERNET \\
$10.000 \mathrm{~km}$ & Planet & \\
\hline
\end{tabular}

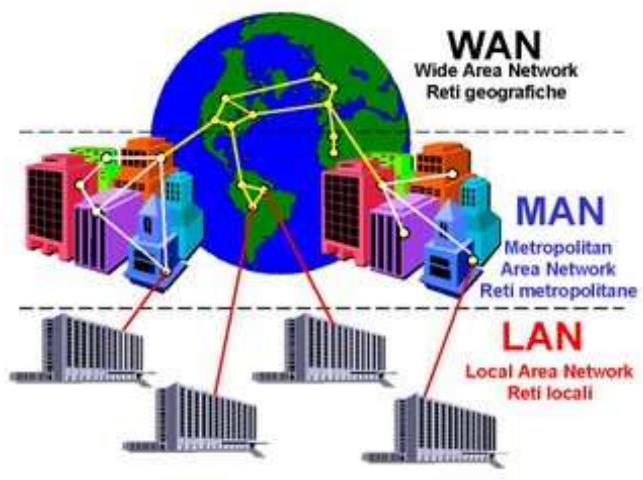

Gambar 1 Jaringan LAN, MAN, WAN

1) Local Area Network (LAN), merupakan jaringan yang saling terhubung ke satu komputer server menggunakan topologi tertentu, biasanya digunakan dalam kawasan satu gedung atau kawasan yang jaraknya tidak lebih dari $1 \mathrm{~km}$.

2) Metropolitan Area Network (MAN), merupakan jaringan yang saling terkoneksi dalam satu kawasan kota dan jaraknya dapat lebih dari $1 \mathrm{~km}$ sehingga menjadi pilihan untuk membangun jaringan komputer antar kantor atau kampus dalam satu kota.

3) Wide Area Network (WAN), merupakan jaringan yang menghubungkan banyak LAN dan MAN kedalam suatu jaringan terpadu, antara satu jaringan dengan jaringan lain dapat berjarak ribuan kilometer atau terpisahkan letak geografi menggunakan metode komunikasi tertentu (Tanenbaum, 1997)

\section{II.3 Topologi Jaringan}

Topologi jaringan komputer secara umum terbagi dalam 6 bentuk sebagai berikut (Tanenbaum, 1997)

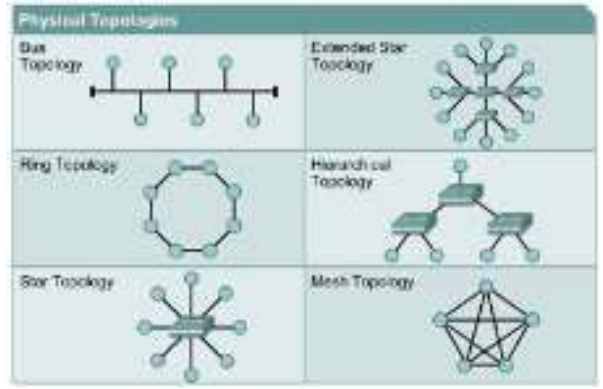

Gambar 2 Topologi Jaringan Komputer

a. Topologi Bus, adalah topologi jaringan yang menggunakan sebuah kabel utama sebagai tulang punggung (backbone). Keuntungan topologi ini adalah hemat kabel, layout kabel sederhana, serta mudah dikembangkan. Kerugiannya adalah deteksi dan isolasi kesalahan sangat kecil, padatnya lalu lintas atau bila salah satu client rusak maka jaringan tidak berfungsi, dan diperlukan repeater untuk menguatkan sinyal untuk jarak jauh.

b. Topologi Ring, adalah topologi jaringan berupa lingkaran tertutup yang berisi node-node. Semua komputer tersambung membentuk lingkaran. Setiap simpul memiliki tingkat yang sama. Jaringan ini disebut loop. Data dikirim ke setiap simpul dan simpul memeriksa alamat informasi yang diterima, apakah untuknya atau tidak. Keuntungan topologi ini adalah pemeliharaan mudah, jarak jangkauan lebih luas daripada topologi Bus, laju data (transfer rate) tinggi, dapat melayani lalu lintas data yang padat, tidak diperlukan pengendali pusat (hub/switch), dan komunikasi antar terminal yang mudah. Kerugiannya adalah penambahan/ pengurangan terminal sangat sulit, tidak kondusif untuk pengiriman suara dan gambar, dan kerusakan pada media pengirim akan menghentikan kerja seluruh jaringan.

c. Topologi Star, adalah topologi jaringan yang menggunakan concentrator (hub/switch) untuk mengatur paket data. Topologi ini memiliki kontrol terpusat. Semua link harus melewati pusat yang menyalurkan data ke semua simpul (client). Simpul pusat disebut stasiun primer (server), simpul lain disebut stasiun sekunder (client server). Setelah hubungan dimulai oleh server, setiap client server dapat menggunakan jaringan tanpa menunggu perintah server. Topologi ini adalah paling fleksibel. Pemasangan/perubahan stasiun sangat mudah dan tidak mengganggu bagian jaringan lain. Juga memiliki kemudahan dalam pengelolaan jaringan. Kerugiannya antara lain adalah boros kabel, dan hub/switch menjadi suatu elemen yang kritis.

d. Topologi Tree, adalah kombinasi topologi Bus dan topologi Star. Dalam topologi ini tidak semua node memiliki kedudukan yang sama. Node berkedudukan tinggi menguasai node di bawahnya sehingga node terbawah sangat tergantung pada node diatasnya. Penerapan teknologi ini biasa digunakan pada infrastruktur jaringan LAN antar gedung.

e. Topologi Mesh, adalah topologi jaringan yang 
semua komputernya saling terkoneksi satu sama lain. Penerapannya pada jaringan WAN.

f. Topologi Wireless. Terdapat 2 jenis topologi yaitu peer-to-peer dan client-server. Pada topologi wireless peer-to-peer, jaringan terhubung pada setiap komputer dalam jaringan dengan lebih mudah dan langsung. Sedangkan pada topologi wireless client-server, harus ada access point untuk memungkinkan komputer menerima/mengirim data

\section{II.4 Wireless (WiFi)}

Wireless (nirkabel) adalah teknologi yang menghubungkan dua piranti untuk bertukar data tanpa media kabel. Adapun Wireless Fidelity (WiFi), yaitu perangkat standar yang digunakan untuk komunikasi jaringan lokal tanpa kabel (Wireless Local Area Network/WLAN) yang didasari pada spesifikasi IEEE 802.11. Beberapa istilah yang digunakan dalam jaringan wireless adalah: (Sopandi, 2008; Pratama, 2015)

a. Wireless Local Area Network (Wireless LAN), yaitu jaringan tanpa kabel yang memanfaatkan gelombang radio sebagai media komunikasi antara perangkat. Frekuensi yang digunakan adalah $2,4 \mathrm{GHz}$ $(802.11 \mathrm{~b}, 802.11 \mathrm{~g}, 802.11 \mathrm{n})$ atau $5 \mathrm{GHz}$ (802.11a). Standarisasi Wireless LAN dibedakan menjadi beberapa jenis, yaitu 802.11a, 802.11b, 802.11g, dan $802.11 \mathrm{n}$.

b. Wireless Fidelity (WiFi) adalah produk/ perangkat yang mengikuti spesifikasi 802.11. Pengguna lebih mengenal wireless card/adapter dibanding 802.11 card/adapter. Awalnya WiFi ditujukan untuk penggunaan perangkat nirkabel dan jaringan area lokal (LAN), namun saat ini lebih banyak digunakan untuk mengakses Internet.

c. Hotspot, adalah bentuk pemanfaatan teknologi Wireless LAN pada lokasi publik. Konsep ini pertama kali dikemukakan pada tahun 1993 oleh Bret Stewart pada Konferensi Networld dan Interop di San Fransisco.

d. Access Point, merupakan titik akses nirkabel (Wireless Access Point) yang memungkinkan piranti nirkabel terhubung ke jaringan dengan $W i$ $\mathrm{Fi}$, Bluetooth, atau standar lain.

e. Captive Portal, adalah halaman web untuk meng-input username dan password pengguna hotspot. Saat client browsing ke internet, akan diarahkan (redirect) ke captive portal terlebih dahulu untuk mengisi username dan password. Bila cocok dengan database pada radius server, sistem akan membuka koneksi pada client sehingga terhubung dengan jaringan internet.

f. Channel, merupakan jalur-jalur pemisah pada jaringan. Peralatan 802.11a bekerja pada frekuensi $5,15-5,875 \mathrm{GHz}$, dan peralatan $802.11 \mathrm{~b}$ serta $802.11 \mathrm{~g}$ bekerja pada frekuansi 2,4-2,497 GHz. Jadi, 802.11a menggunakan pita frekuensi lebih besar daripada $802.11 \mathrm{~b}$ atau 802.11g. Semakin lebar pita frekuensi maka semakin banyak channel yang tersedia.

g. Service Set Identifier (SSID), merupakan identifikasi/ nama jaringan wireless. Setiap wireless harus menggunakan SSID tertentu. Peralatan wireless dianggap satu jaringan jika tergabung pada SSID yang sama. Agar dapat berkomunikasi, setiap peralatan wireless harus tergabung pada SSID dan channel yang sama.

\section{II.5 Router}

Router adalah perangkat yang melewatkan paket IP dari suatu jaringan ke jaringan yang lain menggunakan metode addressing dan protocol tertentu. Router-router yang terhubung dalam jaringan tergabung dalam suatu algoritma routing untuk menentukan jalur terbaik yang dilalui paket IP (Sofana, 2012). Proses routing dilakukan secara hop by hop. IP tidak mengetahui seluruh jalur menuju tujuan setiap paket. IP hanya routing menyediakan IP address dari router berikutnya yang lebih dekat ke host tujuan. Fungsi router sebagai berikut: (Herlambang 2008).

a. Membaca alamat logika/IP address source dan tujuan untuk menentukan routing dari suatu LAN ke LAN lainnya.

b. Menyimpan routing table untuk menentukan rute terbaik antara LAN ke WAN.

c. Perangkat layer ke-3 dalam Open Systems Interconnection (OSI) Layer.

d. Dapat berupa "box" atau sebuah OS yang menjalankan sebuah daemon routing.

e. Interfaces Ethernet, Serial, ISDN BRI.

\section{II.6 Mikrotik Router OS}

Mikrotik adalah sistem operasi independen berbasis Linux, khusus untuk komputer yang berfungsi sebagai router. Mikrotik sangat baik untuk keperluan administrasi jaringan komputer seperti merancang dan membangun sebuah sistem jaringan berskala kecil hingga yang kompleks. Mikrotik digunakan sejak tahun 1995 yang awalnya ditujukan untuk perusahaan jasa layanan internet (Internet Service Provider/ISP).

Saat ini mikrotik memberi layanan kepada banyak ISP untuk layanan akses internet di seluruh dunia. Mikrotik pada hardware berbasis PC dikenal dengan kestabilan, kualitas kontrol, dan fleksibilitas untuk berbagai jenis paket data dan penanganan proses rute (routing). Mikrotik yang dijadikan router berbasis komputer banyak bermanfaat untuk ISP yang ingin menjalankan beberapa aplikasi. Selain routing, mikrotik dapat digunakan sebagai manajemen kapasitas akses, seperti bandwidth, firewall, wireless access point (WiFi), backhaul link, system hotspot, Virtual Private Network Server, dan lainnya. Mikrotik bukan perangkat lunak yang gratis jika ingin dimanfaatkan secara penuh. Dibutuhkan lisensi dari mikrotik untuk menggunakan dengan membayar. Mikrotik dikenal dengan istilah level pada lisensinya, mulai level 0 kemudian 1, 3, hingga 6. Setiap level memiliki kemampuan yang berbeda sesuai harganya. Penjelasan setiap level mikrotik sebagai berikut: (Rendra, 2016).

a. Level 0 (gratis): Tidak membutuhkan lisensi untuk menggunakannya dan penggunaan fitur hanya dibatasi selama 24 jam setelah instalasi dilakukan.

b. Level 1 (demo). Pada level ini user dapat menggunakannya sebagai routing standar dengan 1 pengaturan, dan tidak memiliki limitasi waktu untuk menggunakannya. 
c. Level 3. Level ini mencakup level 1 ditambah kemampuan untuk memanajemen hardware berbasis kartu jaringan atau Ethernet dan pengelolan perangkat wireless tipe client.

d. Level 4. Level ini mencakup level 1 dan 3 ditambah kemampuan untuk mengelola perangkat wireless tipe access point.

e. Level 5. Level ini mencakup level 1, 3, dan 4 ditambah kemampuan mengelola jumlah pengguna hotspot yang lebih banyak.

f. Level 6. Level ini mencakup semua Level dan tidak memiliki limitasi atau batasan apapun.

Berdasarkan fungsi dan bentuknya, mikrotik dibedakan menjadi 2 jenis, yaitu:

a. Mikrotik router OS yang berbentuk perangkat lunak (software), yang dapat diunduh di www.mikrotik.com dan dapat diinstal pada komputer PC.

b. Built-in Hardware Mikrotik yang berbentuk perangkat keras (hardware), yang dikemas dalam board router yang didalamnya sudah terinstal mikrotik router OS.

Untuk melakukan pengembangan jaringan dalam penelitian ini, digunakan perangkat mikrotik router dan administrasinya dilakukan melalui windows application (WinBox). Mikrotik router memiliki banyak fitur seperti firewall dan NAT, Routing-static routing, Data Rate Management, dan hotspot. Mikrotik router mampu menggabungkan 2 line speedy atau lebih kedalam satu router (Load Balance). (Wiliyana, 2014)

\section{METODE PENELITIAN}

Jenis penelitian ini adalah penelitian kualitatif, yaitu berawal pada data dan bermuara pada kesimpulan. Sasaran atau obyek penelitian dibatasi agar data yang diambil dapat digali sebanyak mungkin serta agar penelitian ini tidak dimungkinkan adanya pelebaran obyek penelitian. Karena itu kredibilitas dari penelitian sendiri menentukan kualitas dari penelitian ini. Kategori penelitian ini adalah penelitian lapangan (field research), yaitu penelitian yang dilakukan dengan cara mendatangi langsung tempat yang menjadi objek penelitian.

Penelitian ini mengembangkan jaringan dengan PC sebagai router dengan sistem operasi mikrotik router sehingga termasuk tipe penelitian rekayasa, yaitu penelitian yang menerapkan ilmu pengetahuan menjadi suatu rancangan guna mendapatkan kinerja sesuai dengan persyaratan yang ditentukan. rancangan tersebut merupakan sintetis dari unsur-unsur yang dipadukan dengan ilmiah menjadi model yang memenuihi spesifikasi tertentu. Penelitian diarahkan untuk memenuhi spesifikasi yang ditentukan. Dalam penelitian ini dilakukan perancangan jaringan, yaitu tahap persiapan untuk rancang bangun suatu jaringan yang menggambarkan bagaimana jaringan dibentuk, dapat berupa penggambaran, perencanaan, dan pembuatan sketsa atau pengaturan beberapa elemen terpisah ke dalam satu kesatuan yang utuh, termasuk mengkonfigurasikan komponen software dan hardware suatu jaringan.
Untuk memperoleh data yang dibutuhkan penelitian ini, digunakan teknik sebagai berikut:

a. Observasi, yaitu mengamati langsung lokasi penelitian di SMA PGRI Aikmel untuk melihat kondisi yang ada sehingga diperoleh gambaran akurat mengenai permasalahan yang dihadapi.

b. Wawancara, yaitu melakukan tanya jawab dengan pihak-pihak yang mengetahui secara pasti tentang permasalahan yang dihadapi.

c. Dokumentasi, yaitu mengumpulkan dan mempelajari dokumen-dokumen yang terkait dengan permasalahan yang dihadapi, antara lain gambaran umum SMA PGRI Aikmel, dokumen jaringan yang ada, serta berbagai informasi lain yang mendukung penelitian ini.

d. Kepustakaan, yaitu mempelajari berbagai buku, literatur, artikel di internet, serta bahan pustaka lain yang berhubungan dengan penelitian ini.

Metode pengembangan jaringan dilakukan dengan pendekatan Network Development Live Cycle (NDLC) yang merupakan kunci dibalik proses perancangan jaringan komputer, karena merupakan siklus proses pembangun atau pengembangan sistem jaringan komputer. Langkah-langkah dalam NDLC digambarkan sebagai berikut:

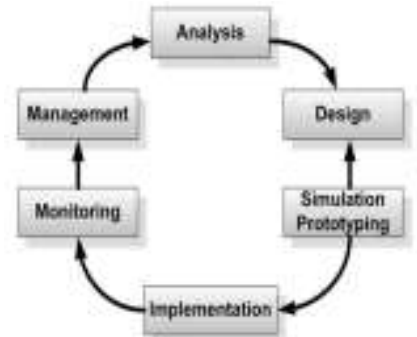

Gambar 3 Network Development Live Cycle.

\section{HASIL PENELITIAN}

\section{IV.1 Analisis Jaringan}

Pada jaringan lama di SMA PGRI Aikmel ini memiliki layanan hostpot yang belum di kelola dengan baik seperti pengaturan user, pembagian bandwitdh dan blokir akses situs yang tidak penting diakses oleh guru dan siswa serta sinyal wirelless yang ada tidak bisa masuk ke ruang kelas belajar sehingga jika siswa ingin mengakses internet hostpot siswa harus keluar dari ruangan kelas atau bisa ke lab langsung seperti gambar berikut.

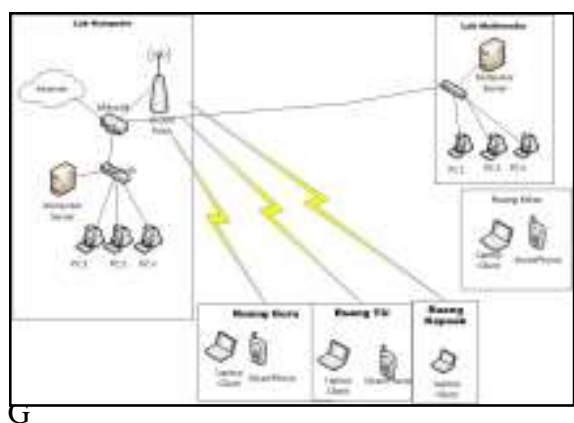

Gambar 4 Skema Jaringan Lama 


\section{IV.2 Desain Jaringan yang dirancang}

Dalam pengembangan jaringan hostpot menggunakan MikroTik RB951Ui-2HnD pada SMA PGRI Aikmel dibutuhkan beberapa perangkat seperti access point yang akan ditaruh di lab multimedia untuk menembak sinyal wireless dari lab komputer agar pancaran sinyal wireless bisa tersebar ke ruang kelas, pada jaringan baru ini akses hostpot sudah di manajemen seperti pembuatan user, pembagian bandwitdh dan akses blokir situs sehingga baik guru dan siswa bisa mengakses internet sesuai jalur masing-masing yang sudah dibuatkan, seperti pada gambar berikut.

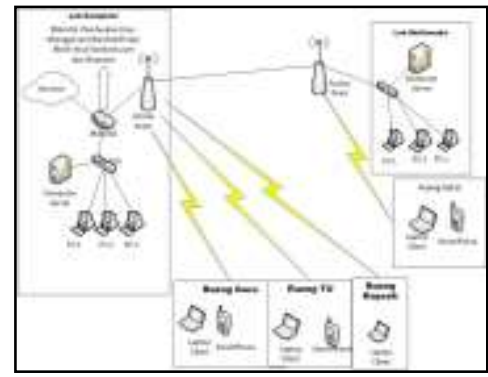

Gambar 5 Skema Baru

Dalam penelitian ini dirancang sebuah jaringan yang memiliki 2 ruang Lab yaitu Lab Komputer dan Lab Multimedia dimana setiap Lab memiliki 1 PC Server dan 30 PC Client dan menggunakan Topology Star serta memiliki layanan hostpot yang kurang lebih memiliki 20 client.

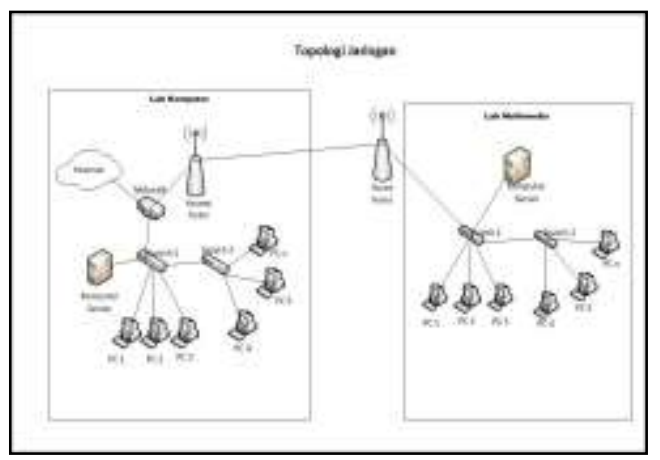

Gambar 6 Topologi Jaringan

\section{IV.3 Implementasi Jaringan (Konfigurasi Mikrotik dan Uji coba)}

Sebelum melakukan konfigurasi setting mikrotik terlebih dahulu dipersiapkan alat-alat yang dibutuhkan seperti Mikrotik RB951Ui-2HnD, Kabel UTP RJ45, akses internet ke mikrotik, PC/Laptop admin dan aplikasi Winbox untuk konfigurasi Mikrotik. Langkah-langkah konfigurasi Router Mikrotik melalui winbox adalah sebagai berikut :

1. Pastikan Mikrotik sudah terhubung dengan arus listrik dan Slot konektor eth1 terhubung dengan internet dan eth2 terhubung dengan laptop/PC Admin

2. Buka Aplikasi winbox yang ada pada laptop admin, kemudian tunggu sampai MAC Address dari mikrotik selanjutnya klik mac address dan klik button connect.

3. Masuk ke dalam tampilan jendela awal winbox dan menampilkan beberapa menu yang digunakan dalam setting mikrotik.

4. Mengganti nama interface agar bisa membedakan mana yang terhubung ke internet dan yang terhub ung ke Laptop/PC admin sebagai LAN, pada jendela winbox pilih menu interface.

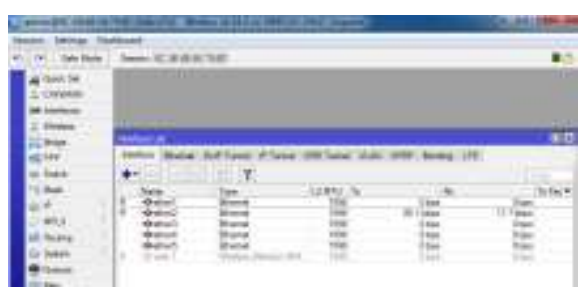

Gambar 7 Tampilan Jendela Interface List

5. Kemudian double klik pada ether yang akan diganti namanya, Pada Name tuliskan nama sesuai dengan nama yang diinginkan lalu klik Apply dan $O K$.

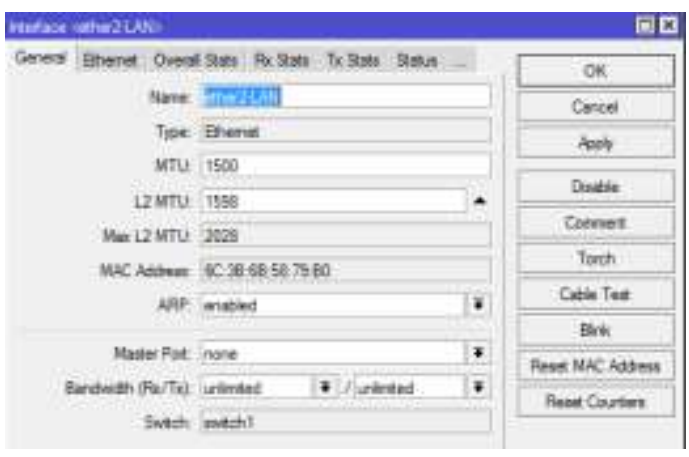

Gambar 8 Tampilan Interface Ether $1 \& 2$

6. Mengaktifkan WLAN1 agar Wireless pada mikrotik bisa berfungsi. Double klik pada wlan1, pilih Mode : ap bridge, Band : $2 \mathrm{GHz}-\mathrm{B} / \mathrm{G} / \mathrm{N}$, Channel Width : 20/40Mhz Ce, Frequency : 2412, SSID : SMAN 1 SUELA selanjutnya klik Enable lalu klik Apply, jika ada perintah yang keluar klik yes dan $O K$.

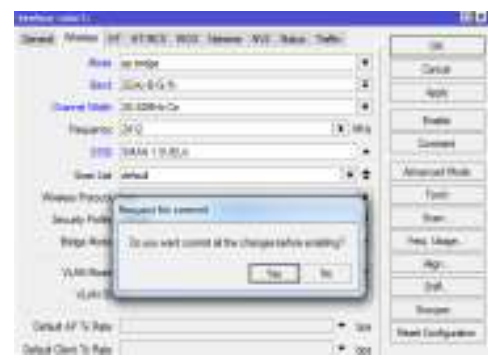

Gambar 9 Mengaktifkan Interface Wlan1

7. Setelah mengganti semua nama ethernet dan mengaktifkan wlan1, masing-masing ethernet pada interface listnya akan otomatis berubah, nama ethernet sesuai dengan nama yang telah dibuat.

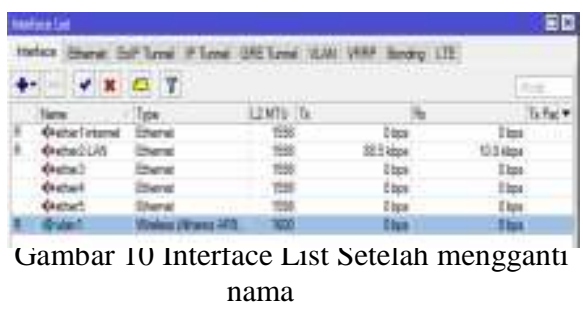


8. Melakukan konfigurasi IP address pada Mikrotik yang bertujuan agar bisa membedakan alamat untuk jaringan LAN dan jaringan WLAN, dengan cara klik menu IP pada jendela winbox dan pilih Address lalu akan tampil seperti gambar berikut.

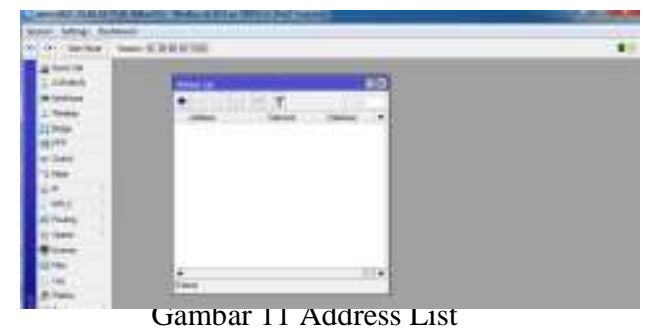

9. Selanjutmya klik tanda (+) pada address list yang tampil. Pada Address masukkan IP untuk Mikrotik yaitu 192.168.10.1/24 dan pada interface pilih ether2LAN lalu klik Apply maka network akan otomatis muncul lalu.

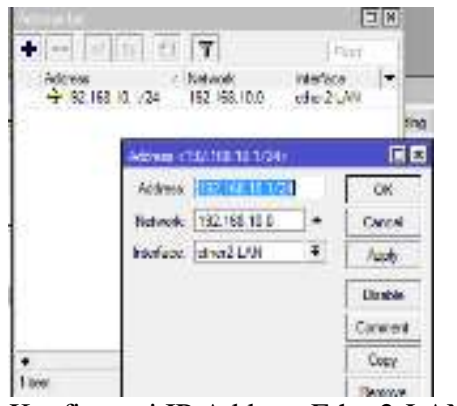

Gambar 12 Konfigurasi IP Address Ether2-LAN

10. Konfigurasi IP address untuk wlan1 dengan cara klik tanda (+) pada address list lalu ketikkan IP address 192.168.20.1/24 dan pada interface pilih wlan1 lalu Apply maka network akan muncul otomatis dan OK.

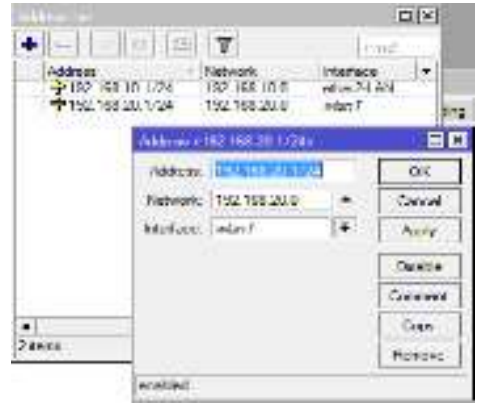

Gambar 13 Konfigurasi IP Address pada Interface Wlan1

11. Apabila IP Address sudah dikonfigurasikan maka akan tampil pada Address listnya seperti gambar berikut.

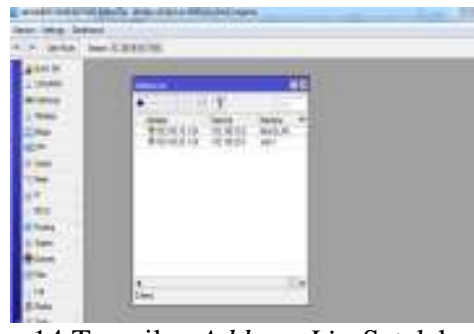

Gambar 14 Tampilan Address List Setelah ditambahkan IP Address
12. Selanjutnya mengkonfigurasi DHCP Client, yang bertujuan agar setiap client yang terhubung dengan jaringan akan mendapatkan IP Addrees secara otomatis. Langkahnya: klik menu IP $\rightarrow$ pilih DHCP client $\rightarrow$ klik tanda $(+) \rightarrow$ interface $=$ ether1-internet dan Default Route Distance $=1 \rightarrow$ lalu klik Apply $\rightarrow$ OK. Pastikan status DHCP client sudah menjadi bound agar bisa ke tahap konfigurasi selanjutnya.

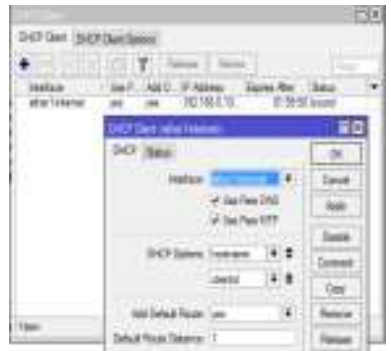

Gambar 15 Konfigurasi DHCP Client

13. Mengkonfigurasi DNS (Domain Name System) di mana DNS ini berfungsi untuk menyimpan informasi nama dan host domain yang tersebar didalam jaringan komputer, biasanyaDNS menggunakan alamat IP melalui gateway dari IP ISP atau DNS Google. Konfigurasinya pada menu winbox klik IP $\rightarrow$ pilih DNS- $\rightarrow$ Server masukkan IP 8.8.8.8 dan 8.8.4.4 ini adalah DNS default Google $\rightarrow$ centang Allow Remote Request $\rightarrow$ Apply $\rightarrow \mathrm{OK}$.

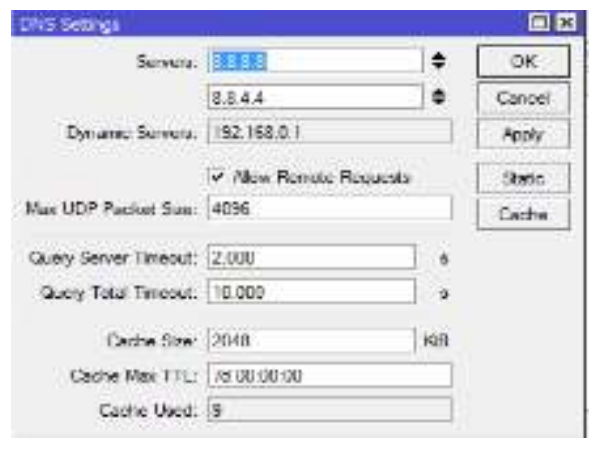

Gambar 16 Konfigurasi DNS Server

14. Konfigurasi NAT rule dimana NAT (Network Address Translation) ini digunakan pada jaringan dengan workstation yang menggunakan IP private supaya dapat terkoneksi ke internet. Pastikan pada saat konfigurasi NAT rule harus terhubung dengan etherl-internet, adapun langkah-langkahnya sebagai berikut : klik menu IP $\rightarrow$ pilih Firewall $\rightarrow$ klik NAT $\rightarrow$ klik tanda $(+) \rightarrow$ pastikan Chain diisi srcnat, Out interface : ether1-internet $\rightarrow$ pada menu action pilih masquerade $\rightarrow$ Apply Lalu OK.

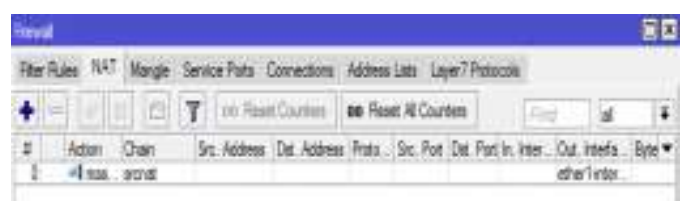

Gambar 17 Tampilan Jendela Firewall Setelah Konfigurasi NAT 
15. Selanjutnya adalah untuk memastikan apakah mikrotik sudah terkoneksi dengan internet. Yang perlu dilakukan adalah melakukan tes Ping. Langkahnya adalah klik menu terminal $\rightarrow$ didalam jendela terminal masukkan perintah "ping google.com" dan "ping 8.8.8.8" lalu enter dan jika status TTL berjalan maka proses ping berhasil dan mikrotik sudah terkoneksi dengan akses internet, seperti gambar 4.18

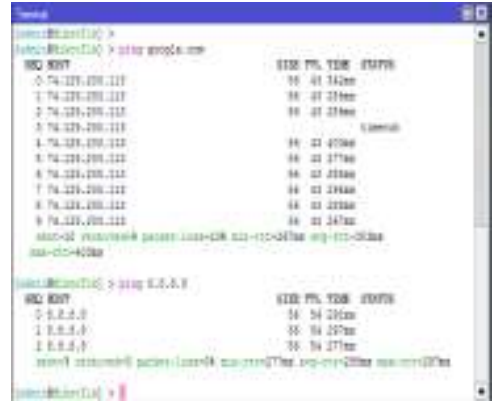

Gambar 18 Proses Ping Google dan DNS

16. Setting IP addres pada Local area connection pada laptop admin agar internet bisa berjalan pada laptop admin dan jaringan LAN

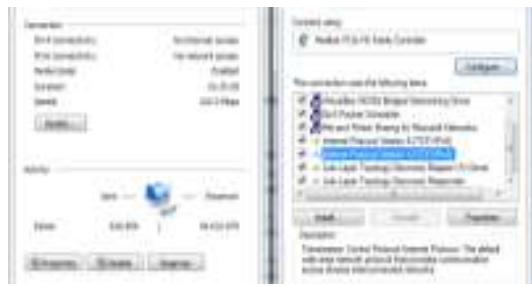

Gambar 19 Proses Setting Local Area Connection Laptop Admin

17. Pada proses pengisian IP Address di Laptop Admin disini menggunakan Ip dengan Ether1-LAN yang sudah di konfigurasi sebelumnya di mikrotik sebagai gateway agar jaringan bisa terhubung dengan LAN.

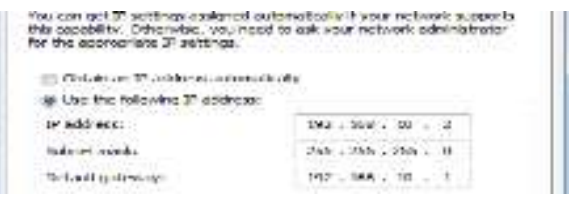

Gambar 20 Memasukan IP Addres LAN

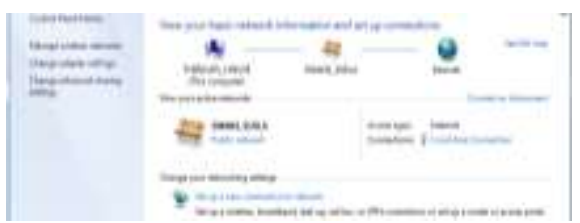

Gambar 21 Jaringan LAN Sudah Terhubung

18. Setelah tes koneksi berhasil dan jaringan LAN sudah terhubung internet dilakukan setting SNTP agar nantinya pada saat memblok situs bisa terblok. Adapun langkah-langkahnya : Klik menu system $\rightarrow$ SNTP Client $\rightarrow$ pada jendela SNTP Client centang enable $\rightarrow$ primary NTP Server isi dengan : 0.id.pool.ntp.org dan Secondary NTP Server isi dengan : 1.id.pool.ntp.org $\rightarrow$ Apply $\rightarrow \mathrm{OK}$, setelah mengklik Apply secara otomatis primary dan secondary NTP server akan berubah menjadi IP Address.

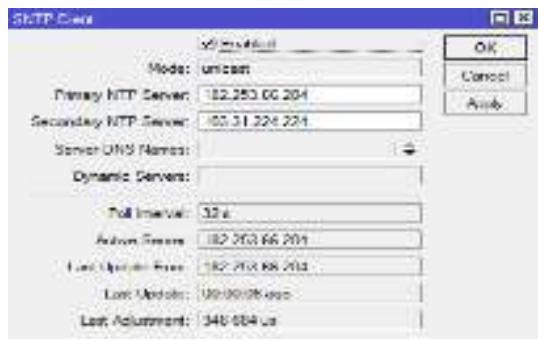

Gambar 22 SNTP Berubah Menjadi IP

19. Mengatur waktu lokasi berdasarkan zona atau area Langkah pengaturannya adalah klik menu system $\rightarrow$ pilih clock $\rightarrow$ pilih time zone : Asia/Makasar $\rightarrow$ Apply $\rightarrow$ OK.

20. Memblokir situs Facebook.com menggunakan 7 layer protocol, adapun langkah-langkanya adalah klik menu $\quad I P \rightarrow$ pilih $\quad$ Firewall $\rightarrow$ kilik 7 layer protocol $\rightarrow$ klik tanda add $(+) \rightarrow$ pada kotak 7 layer protocol tulis name : medsos, pada text area Ragexp ketikkan perintah yaitu ${ }^{\wedge}$.+(facebook.com). $* \$ \rightarrow$ klik Apply $\rightarrow \mathrm{OK}$. Begitu juga proses yang dilakukan untuk memblokir situs yang lainnya.

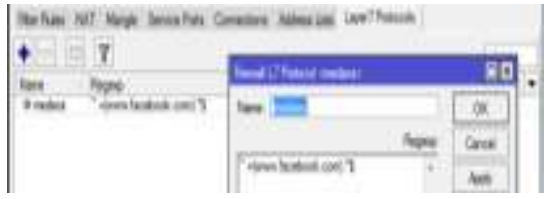

Gambar 23 Proses Blokir Situs Facebook.com

21. Mengaktifkan konfigurasi blokir situs di atas dengan setting filter firewall rule. Langkahnya adalah klik Filter Rules $\rightarrow$ klik add $(+) \rightarrow$ pada jendela Firewall Rule pilih general chain : forward, src address : 192.168.10.0/24 $\rightarrow$ menu advance pilih layer 7 protocol : medsos / nama dari blokiran yang sudah dibuat $\rightarrow$ menu action pilih drop $\rightarrow$ Apply $\rightarrow \mathrm{OK}$.

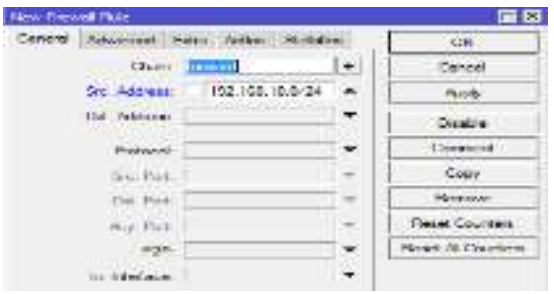

Gambar 24 Mengaktifkan Blokir IP Address

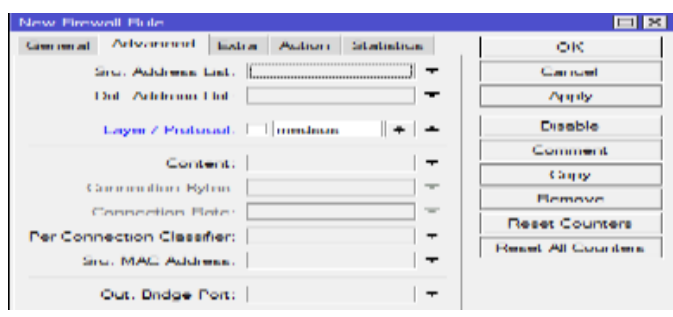

Gambar 25 Mengaktifkan Blokir Layer 7 Protocol

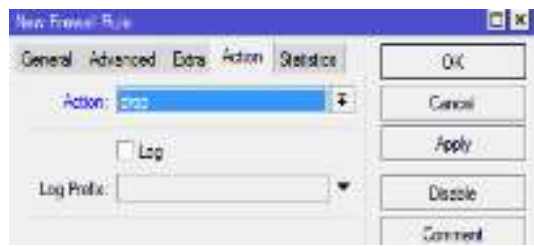


Gambar 26 Mengaktifkan Blokir Action Drop

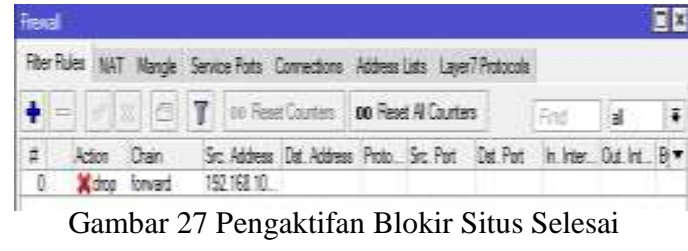

Proses mengaktifkan akses blokir sudah selesai dilakukan dan akan di tes diakhir nanti.

22. Membuat Hostpot untuk jaringan diluar Lab yang nantinya akan diakses oleh para guru dan siswa/siswi yang ada di SMA PGRI Aikmel. Adapun langkah-langkahnya yaitu : klik menu IP $\rightarrow$ pilih Hostpot $\rightarrow$ pada jendela hostpot klik Hostpot setup $\rightarrow$ pilih wlan1 selanjutnya tinggal di next terus sampai selesai, DNS Name disini menggunakan www.smapgriaikmel.sch.id,

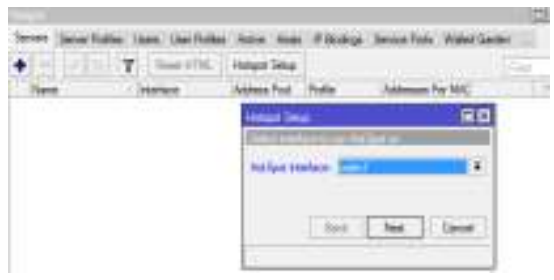

Gambar 28 Mengaktifkan Fitur Wlan

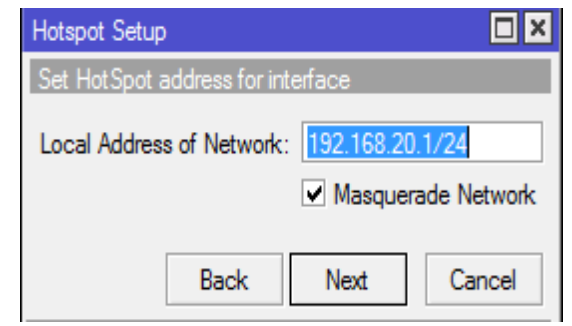

Gambar 29 IP Address Wlan

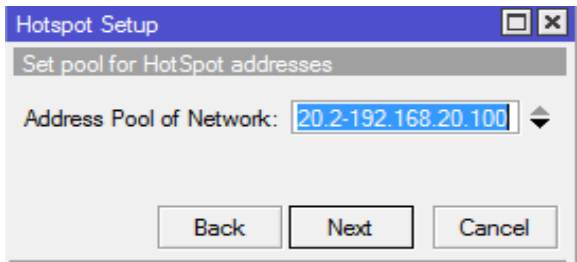

Gambar 30 Address Pool Network

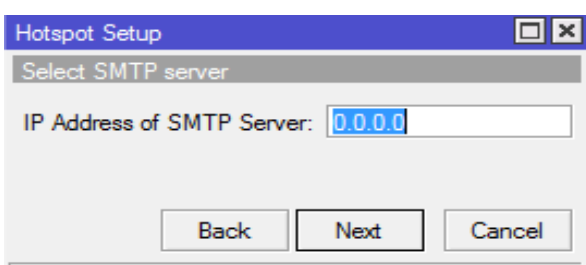

Gambar 31 IP Address SMTP Server

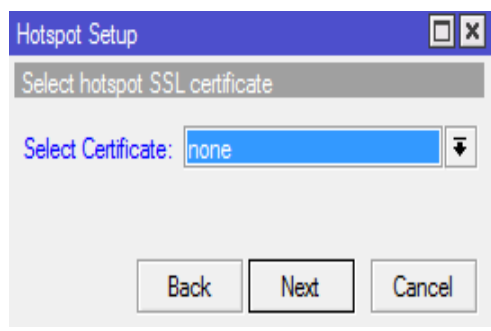

Gambar 32 Pemilihan Certificate

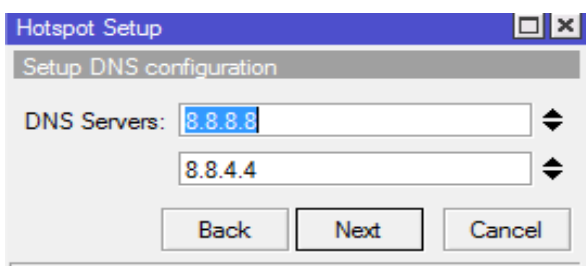

Gambar 33 Alamat DNS Server

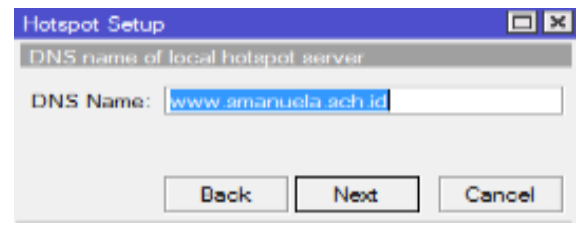

Gambar 34 DNS Name

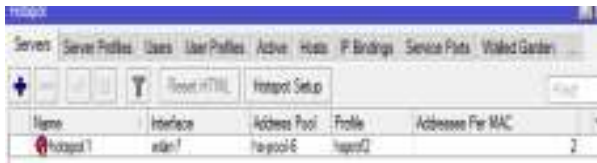

Gambar 35 Pembuatan Hostpot Berhasil

23. Membuat user profile bagi guru dan siswa. Untuk pembuatan user profile ada di menu user profile dan pembuatan user name dan password ada dimenu user dan pembagian bandwitdh. Setiap guru diberi akses unlimited dan siswa dibatasi dengan mendapatkan 256k/256,

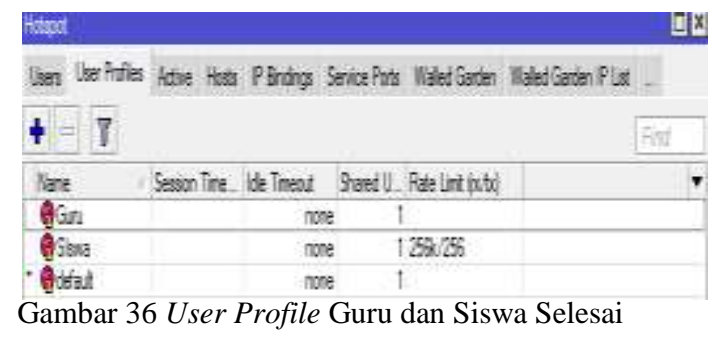

24. Membuat user name dan password bagi guru dan siswa dimana akan digunakan pada saat mengakses hostpot.

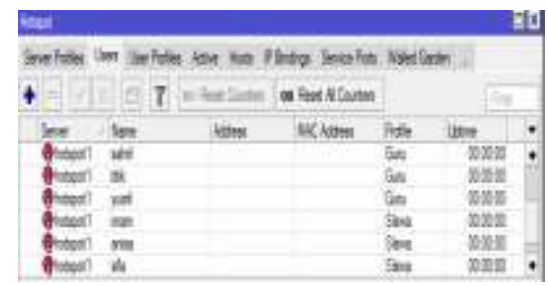

Gambar 37 Pembuatan User Guru dan Siswa

25. Proses Konfigurasi Mikrotik dan Pembuatan Hostpot sudah selesai, selanjutnya melakukan tes 
koneksi di client yang sudah dibuat sebelumnya dimana guru dan siswa bisa mengakses internet melalui Smart Phone maupun Laptop yang punya kapasitas wifi.

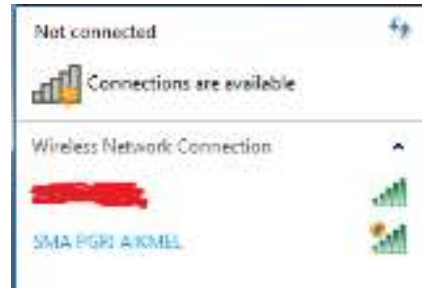

Gambar 38 Tampilan Sinyal WLAN

26. Koneksikan hostpot dan melakukan tes login dengan user guru pada aplikasi browser, untuk proses login isikan user name dan password yang sudah dibuatkan maka tampilan awalnya di browser seperti gambar berikut.

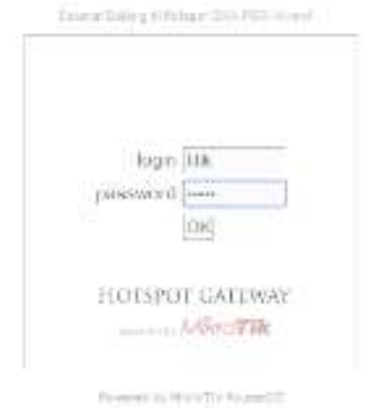

Gambar 39 Proses Login User Guru

27. Jika user name dan password sudah dimasukkan maka akan muncul keterangan welcome nama user, IP Address, connect dan status pengguna, maka proses Login berhasil.

welcarme bitik!

\begin{tabular}{|r|l|}
\hline IP address: & $192.168 .20,967$ \\
\hline bytes up/down: & $298 \mathrm{~B} / 48 \mathrm{~B}$ \\
\hline connected: & 09 \\
\hline status refresh: & im \\
\hline
\end{tabular}

\section{$\log$ an}

Gambar 40 Login Berhasil

28. Testing membuka situs facebook yang sudah diblokir pada konfigurasi mikrotik. Apabila blokir situs berhasil maka pada browser akan muncul kalimat "Sorry something went wrong" itu artinya situs yang diblok sudah berhasil dan tidak bisa terbuka.

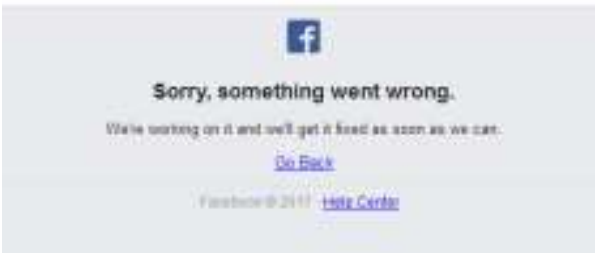

Gambar 41 Testing Blok Facebook Berhasil

29. Begitupun dengan testing situs Xhamster yang sudah diblokir pada konfigursasi mikrotik, pada saat diakses akan muncul kalimat yang menandakan situs tidak bisa diakses " Page not found ".

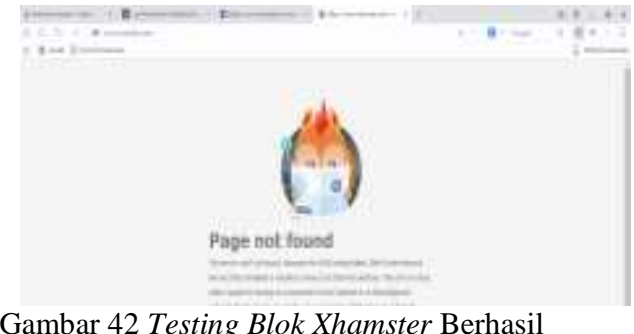

Gambar 42 Testing Blok Xhamster Berhasil

Proses Konfigurasi mikrotik dan pembuatan Hostpot serta pembagian bandwitdh dan akses blokir situs facebook sudah selesai dan siap diakses oleh guru dan siswa.

\section{KESIMPULAN DAN SARAN}

Hasil penelitian ini menunjukkan bahwa pengembangan jaringan wireless menggunakan Mikrotik Router dengan memanfaatkan Personal Computer (PC) sebagai router untuk mengolah dan mengkonfigurasikan management bandwidth, web filtering, dan user management dapat mengamankan dan mengoptimalkan pemakaian jaringan nirkabel pada SMA PGRI Aikmel.

Untuk dapat memaksimalkan performa pengembangan jaringan nirkabel yang dilakukan dalam penelitian ini, perlu dilakukan penambahan kapasitas bandwitdh dan dalam pengembangan jaringan selanjutnya jaringan nirkabel ini dapat dilakukan peningkatan keamanan jaringan dari serangan seperti hacking hotspot.

\section{REFERENS}

Herlambang, M. Linto \& Catur, Azis. 2008. Panduan Lengkap Menguasai Router. Yogyakarta: Andi Offset

Pratama, Romadhon Pearl. 2015. Analisis Kinerja Jaringan Wireless LAN Menggunakan Metode QOS dan RMA Pada PT. Pertamina Ep Ubep Ramba (Persero). Palembang: Program Pascasarjana Univ. Bina Darma.

Rendra, T. 2016. Mikrotik Kung Fu Kitab 1. Palu : Jasakom.

Sopandi. 2008. Instalasi dan Konfigurasi Jaringan Komputer. Bandung: Informatika

Sofana, I. 2012. Cisco CCNA dan Jaringan Komputer. Bandung: Informatika.

Tanenbaum, Andrew S. 1997. Jaringan Komputer. Jilid 1 \& 2. Edisi Ketiga. Yogyakarta: Salemba Teknika

Wiliyana, Dian. 2014. Perancangan Jaringan LAN dan Keamanan Wireless Internet Hotspot Berbasis Mikrotik Router Pada Pomdam IV Sriwijaya. Palembang: Program Pascasarjana Univ. Bina Darma. 